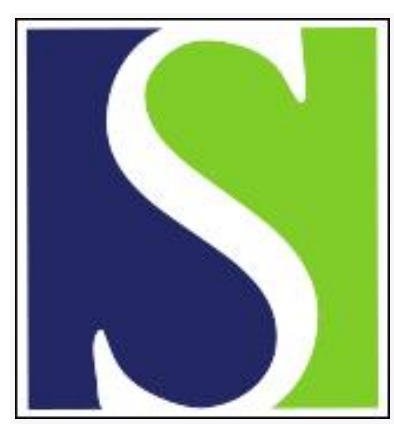

Scand J Work Environ Health 2007;33(6):435-439

https://doi.org/10.5271/sjweh.1165

Issue date: 31 Dec 2007

\title{
Ischemic stroke and shift work
}

by Hermansson J, Gillander Gådin K, Karlsson B, Lindahl B, Stegmayr B, Knutsson A

Affiliation: Fyrbåksvägen 3, SE-722 10, Västerås, Sweden. hermansson-jonas@yahoo.se

Refers to the following texts of the Journal: 1999;25(2):85-99

2005;31(1):30-35

The following articles refer to this text: 2018;44(3):229-238;

2022;48(1):31-40

Key terms: cardiovascular disease; case-control study; epidemiology; ischemic stroke; risk factor; shift work

This article in PubMed: www.ncbi.nlm.nih.gov/pubmed/18327511

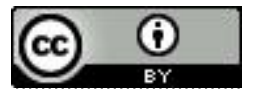




\title{
Ischemic stroke and shift work
}

\author{
by Jonas Hermansson MSc, ${ }^{1}$ Katja Gillander Gådin, PhD, ${ }^{1}$ Berndt Karlsson, MD, ${ }^{2}$ Bernt Lindahl, MD, ${ }^{2}$ \\ Birgitta Stegmayr, PhD, ${ }^{3}$ Anders Knutsson, $M D^{1}$
}

\begin{abstract}
Hermansson J, Gillander Gådin K, Karlsson B, Lindahl B, Stegmayr B, Knutsson A. Ischemic stroke and shift work. Scand J Work Environ Health. 2007;33(6):435-439.

Objectives This study analyzed the potential association between shift work and ischemic stroke.

Methods The analysis was carried out using a nested case-control study consisting of 138 shift workers and 469 day workers from the register of the Northern Sweden Monitoring of Trends and Determinants in Cardiovascular Diseases (MONICA) study and the Västerbotten Intervention Programme. Logistic regression analysis was used to analyze the risk estimate for day workers in a comparison with shift workers and the risk of ischemic stroke.

Results The crude odds ratio for the shift workers' risk of experiencing an ischemic stroke was 1.0 (95\% confidence interval $0.6-1.8$ ) for both the men and the women. The risk estimates were consistent despite the introduction of several recognized risk factors for ischemic stroke in the logistic regression models.

Conclusions In the present study, none of the findings indicated a higher risk of shift workers undergoing an ischemic stroke than day workers.
\end{abstract}

Key terms cardiovascular disease; case-control study; epidemiology; risk factor.

Shift work has been found to be associated with health consequences such as fatigue, sleep disturbance, and gastrointestinal malfunction. Strong evidence has also linked shift work with compromised pregnancy outcome (1). Shift workers also demonstrate up to a $40 \%$ higher risk of myocardial infarction than that of day workers (2). The cause of this increased risk has not yet been clarified in detail. Most of the research on cardiovascular disease among shift workers has focused on the risk of developing myocardial infarction, despite the similarities in risk factors between myocardial infarction and ischemic stroke, for example, smoking and high blood pressure (3). Only a few studies have analyzed the potential association between shift work and stroke, with inconsistent results $(4,5)$. Karlsson et al (4) did not find any statistically significant difference between shift and day workers in a Swedish study cohort, while Virtanen \& Notkola (5) found shift work to be the most influential factor with respect to the risk for cerebrovascular deaths in a Finnish cohort.

The aim of this study was to analyze the potential association between shift work and ischemic stroke.

\section{Study population and methods}

\section{Study population}

This nested case-control study was formed by combining two population-based health surveys, the Northern Sweden Monitoring of Trends and Determinants in Cardiovascular Diseases (MONICA) study and the Västerbotten Intervention Programme (VIP).

The MONICA study started in 1985 in two counties in northern Sweden, Västerbotten and Norrbotten, In general, 250 randomly selected persons of each gender and age group (25-34, 35-44, 45-54, 55-64, and 65-74 years) were invited to participate in health surveys in 1986, 1990, 1994, 1999, and 2004. The oldest age group was only invited to the last three surveys (6). The average participation rate in the five health surveys was $77.2 \%$.

VIP is an ongoing intervention program focusing on cardiovascular disease and diabetes prevention in Västerbotten County. Participants are asked to take part in a health survey, comparable to the MONICA population

1 Department of Health Sciences, Mid Sweden University, Sundsvall, Sweden.

2 Department of Public Health and Clinical Medicine, Occupational Medicine, University of Umeå, Umeå, Sweden.

3 Department of Public Health and Clinical Medicine, Medicine, University of Umeå, Umeå, Sweden.

Correspondence to: Jonas Hermansson, Fyrbåksvägen 3, SE-722 10, Västerås, Sweden. [E-mail: hermansson-jonas@yahoo.se] 
surveys, at their primary health care center when they turn 30,40, 50, and 60 years of age (7). The overall participation rate for VIP has been $60 \%$. The assessment of social characteristics between the participants and nonparticipants has shown little evidence of selection bias (8). Between 1 January 1985 and 31 September 2000, about 66300 individuals had participated in the VIP and MONICA health surveys.

Event registration and case finding. The registration of acute stroke events started in 1 January 1985. Case findings were based on reports from hospitals and general practitioners and on the screening of hospital discharge registers and all death certificates. For both counties, the registration of stroke events was carried out at the Umeå University Hospital. The diagnosis of stroke events was based solely on clinical presentation. In fatal cases, the data from death certificates and from necropsy reports were used to complete the diagnosis (6). Only the cases that occurred after the health survey were included.

The case findings of fatal stroke events cover the following death certificate diagnoses: cerebrovascular disorders, atherosclerosis, multi-infarct dementia, and sudden death appearing as the immediate, underlying, or contributing cause of death. Medical documentation was collected and checked against the World Health Organization (WHO) MONICA stroke criteria (9). All general practitioners in the area were requested to report nonhospitalized cases. Annually, computer-based lists of discharge diagnoses from acute-care hospitals and nursing homes were screened for additional cases.

Stroke was defined according to the WHO criteria as "rapidly developing clinical signs of focal (or global) disturbance of cerebral function lasting more than 24 hours (unless interrupted by surgery or death), with no apparent cause other than a vascular origin" $(9,10)$. All cases of acute stroke in the age range of 25 through 74 years were included from 1985 onwards.

Brain lesions discovered by computed tomography (CT) but not accompanied by acute focal signs were not accepted as stroke cases, nor were extradural and subdural hemorrhages. Stroke cases associated with a brain tumor, trauma, or severe blood disorders or subdural hemorrhage were also excluded.

Table 1. Total number of cases and controls included in this analysis.

\begin{tabular}{lccccc}
\hline Group & \multicolumn{2}{c}{ Men } & & \multicolumn{2}{c}{ Women } \\
\cline { 2 - 3 } \cline { 5 - 6 } & $\begin{array}{c}\text { Day } \\
\text { workers } \\
(\mathrm{N})\end{array}$ & $\begin{array}{c}\text { Shift } \\
\text { workers } \\
(\mathrm{N})\end{array}$ & & $\begin{array}{c}\text { Day } \\
\text { workers } \\
(\mathrm{N})\end{array}$ & $\begin{array}{c}\text { Shift } \\
\text { workers } \\
(\mathrm{N})\end{array}$ \\
\hline Cases & 85 & 21 & & 65 & 23 \\
Controls & 183 & 45 & & 136 & 49 \\
\hline
\end{tabular}

In this paper, only ischemic stroke has been included. The diagnosis of ischemic stroke, according to the MONICA manual, was based on the definition from the International Classification of Diseases, ninth revision (ICD-9 code in parentheses) as follows: brain infarction or ischemic stroke (ICD 434) and no signs of hemorrhage in a CT scan or at necropsy.

Only cases classified as definite events were included as nonfatal cases. In fatal events, possible infarction and unclassified infarction were included (11).

Controls. For each case, five matched controls without known cardiovascular disease and cancer were selected from the MONICA and VIP cohorts. Matching was done according to gender, age ( \pm 2 years), type (MONICA or VIP), and date ( \pm 1 year) of the health survey, and geographic area. Each control received a questionnaire with items on any cardiovascular event that had occurred since the baseline survey. As a first choice, the first two of the controls selected were used in the analyses. If neither of them responded, the third (or occasionally the fourth) control selected was used. The Research Ethics Committee of Umeå University, Umeå, and the data-handling procedures by the National Computer Data Inspection Board, Stockholm, Sweden, approved the study protocol.

Number of day workers and shift workers in the analysis. The material consisted of 834 respondents (table 1), 138 shift workers and 469 day workers. Because of the lack of information about worktimes, 227 respondents were excluded from the analysis. This analysis was only performed for ischemic stroke and included 194 cases, of which 44 cases were exposed to shift work.

\section{Health examination}

Every person selected for participation was invited to a health examination at the nearest health care center, where risk factors such as body mass index (BMI), fasting glucose, blood pressure, total serum cholesterol, and triglyceride levels were examined. The participants were also asked to complete a questionnaire that included, for example, questions about marital status, tobacco habits, educational level, work conditions, and previously known cardiovascular disease.

\section{Exposure information}

The exposure characteristics of the day and shift workers are presented in table 2 .

Shift work. In our study, the shiftwork variable was based on the responses to two questions from the population surveys, since the question regarding workhours was not 
consistent in all the surveys. One question was from the VIP study ["Do you have shift work or weekend work? yes (a) or no (b)"], and the other question came from the MONICA study ["What are your normal workhours? Regular workhours (a), shift work (b), variable workhours (c) and I am not gainfully employed (d)"]. The respondents who answered "a" to the first question and those who responded "b" or "c" to the second question were regarded as shift workers and coded 1 . The others were considered not shift workers and were coded 0 .

Smoking. The alternatives regarding tobacco smoking habits were daily smoker (a), former daily smoker (b), and nonsmoker and occasional smoker (c). Nonsmokers (b and c) were coded 0 , and smokers (a) were coded 1 .

Job strain. The concept of job strain was introduced in 1979 (12). In this study, the demand-control model was used. Job strain was measured using a short version of the questionnaire in Swedish (13). It had five questions about psychological demands and six questions about decision latitude, each with four graded responses ranging from $1=$ never to $4=$ always or almost always. The work experience during the last 5 years prior to inclusion in the study was considered. The variable was based on the individual quota between demand and control. Job strain was considered present for the respondents who were in the upper tertile for the demand questions and the lower tertile for decision latitude. The participants with job strain were coded 1 , and the others were coded 0 .

Educational level. The educational level of the participants was obtained from the question "What is the highest level of education that you have completed?" The respondents were categorized into two groups consisting of those with compulsory school (9 years) level as their highest educational level and those with more than mandatory education. This group included the upper secondary school, higher education, and vocational training. The variable was coded 0 for higher education and 1 for lower education.

Blood pressure. Blood pressure was recorded with a mercury sphygmomanometer after a 5-minute rest in a sitting position (10). For the participants from the VIP survey whose blood pressure was measured only in the recumbent position, an adjustment was made for blood pressure measurement in a sitting position (14). High blood pressure was identified if a participant had a systolic pressure of $\geq 140 \mathrm{mmHg}$ or a diastolic pressure of $\geq 90 \mathrm{mmHg}$ or was on antihypertensive medication. The participants with a blood pressure consistent with this description were coded 1 , and those with a systolic blood pressure of $<140 \mathrm{mmHg}$ and a diastolic blood pressure
Table 2. Exposure characteristics (\%) of the day and shift workers in this analysis.

\begin{tabular}{|c|c|c|c|c|c|c|}
\hline \multirow[t]{2}{*}{ Characteristic } & \multicolumn{3}{|c|}{ Men } & \multicolumn{3}{|c|}{ Women } \\
\hline & $\begin{array}{c}\text { Shift } \\
\text { workers } \\
(\%)\end{array}$ & $\begin{array}{c}\text { Day } \\
\text { workers } \\
(\%)\end{array}$ & P-value & $\begin{array}{c}\text { Shift } \\
\text { workers } \\
(\%)\end{array}$ & $\begin{array}{c}\text { Day } \\
\text { workers } \\
(\%)\end{array}$ & P-value \\
\hline Job strain & 14.8 & 20.9 & 0.284 & 35.9 & 21.6 & 0.025 \\
\hline Smoking & 15.6 & 15.8 & 0.995 & 21.2 & 26.6 & 0.421 \\
\hline Low education & 54 & 54.2 & 0.994 & 61.8 & 60.5 & 0.858 \\
\hline $\begin{array}{l}\text { High serum } \\
\text { triglycerides }\end{array}$ & 20.5 & 18.5 & 0.771 & 5.0 & 6.2 & 0.766 \\
\hline $\begin{array}{l}\text { High serum total } \\
\text { cholesterol }\end{array}$ & 43.1 & 36.6 & 0.346 & 50 & 40.7 & 0.148 \\
\hline $\begin{array}{l}\text { High blood } \\
\text { pressure }\end{array}$ & 43.8 & 52.9 & 0.191 & 57.6 & 50.8 & 0.34 \\
\hline
\end{tabular}

of $<90 \mathrm{mmHg}$ were coded 0 . In the group of participants with high blood pressure, there were 124 who were being medically treated for high blood pressure.

Blood lipids. The total serum cholesterol and triglyceride concentrations were measured using a benchtop analyzer (Reflotron, Boehringer Mannheim GmbH Diagnostica, Mannheim, Germany) at the time of the health survey (VIP) or by an enzymatic method (Boehringer Mannheim GmbH Diagnostica) at a central laboratory (MONICA). These methods have shown a high correlation (15). Plasma samples were obtained from the participants after a minimum of 4 hours of fasting and were thereafter stored in a deep-freeze blood bank at $-80 \mathrm{C}^{\circ}$. The participants with total serum triglyceride levels of $\geq 2.3 \mathrm{mmol} / \mathrm{l}$ or total serum cholesterol levels of $\geq 6.45 \mathrm{mmol} / \mathrm{l}$ were considered at risk for ischemic stroke. Those with a value under the limit were coded 0 , and those with a value equal to or over the limit were coded 1 .

\section{Statistical methods}

For the risk factor variables, the differences were analyzed with chi-square tests. A P-value of $<0.05$ was considered statistically significant. To determine the risk of shift workers developing ischemic stroke, we calculated the odds ratios (OR) with $95 \%$ confidence intervals $(95 \% \mathrm{CI})$. An unconditional logistic regression was used since the conditional logistic regression yielded similar results. The relationship between shift and day work and the outcome of ischemic stroke was assessed in two different models of logistic regression analysis. In model 1 social variables were analyzed, and in model 2 biological variables were analyzed. The data of the men and women were analyzed separately, and both models were adjusted for age. The average age of the participants at the time of inclusion in the study 
Table 3. Age-adjusted odds ratios (OR) and 95\% confidence intervals $(95 \% \mathrm{Cl})$ for shift work in comparison with day work, with adjustment for different confounding variables-results of the multiple logistic regression analysis.

\begin{tabular}{|c|c|c|c|c|}
\hline \multirow[t]{2}{*}{ Predictors } & \multicolumn{2}{|c|}{ Men } & \multicolumn{2}{|c|}{ Women } \\
\hline & $\mathrm{OR}$ & $95 \% \mathrm{Cl}$ & $\mathrm{OR}$ & $95 \% \mathrm{Cl}$ \\
\hline \multicolumn{5}{|l|}{ Model 1} \\
\hline Shiftwork versus daywork & 1.0 & $0.6-1.8$ & 1.0 & $0.6-1.8$ \\
\hline Shiftwork versus daywork, job strain & 1.3 & $0.7-2.3$ & 1.0 & $0.5-1.9$ \\
\hline Shiftwork versus daywork, smoking & 1.0 & $0.6-1.8$ & 1.1 & $0.6-2.0$ \\
\hline $\begin{array}{l}\text { Shiftwork versus daywork, } \\
\text { low educational level }\end{array}$ & 1.0 & $0.6-1.9$ & 1.1 & $0.6-2.0$ \\
\hline $\begin{array}{l}\text { Shiftwork versus daywork, job strain, } \\
\text { smoking, low educational level }\end{array}$ & 1.2 & $0.6-2.3$ & 1.0 & $0.6-2.0$ \\
\hline \multicolumn{5}{|l|}{ Model 2} \\
\hline Shiftwork versus & 1.0 & $0.6-1.8$ & 1.0 & $0.6-1.8$ \\
\hline $\begin{array}{l}\text { Shiftwork versus daywork, } \\
\text { high serum triglycerides }\end{array}$ & 1.0 & $0.5-2.0$ & 1.0 & $0.5-1.9$ \\
\hline $\begin{array}{l}\text { Shiftwork versus daywork, } \\
\text { high serum total cholesterol }\end{array}$ & 1.0 & $0.5-1.8$ & 0.9 & $0.5-1.6$ \\
\hline $\begin{array}{l}\text { Shiftwork versus daywork, } \\
\text { high blood pressure }\end{array}$ & 0.9 & $0.5-1.8$ & 0.6 & $0.3-1.2$ \\
\hline $\begin{array}{l}\text { Shiftwork versus daywork, high serum } \\
\text { triglycerides, high serum total } \\
\text { cholesterol, high blood pressure }\end{array}$ & 1.1 & $0.5-2.2$ & 0.9 & $0.4-1.7$ \\
\hline
\end{tabular}

was 54.7 years, ranging from 30 to 74 years. All of the statistical calculations were carried out using SPSS 12.0 (SPSS Inc, Chicago, IL, USA).

\section{Results}

No statistically significant differences were found between the day and shift workers regarding smoking, high serum triglycerides, high total serum cholesterol, job strain, or educational level (table 3 ).

The results of the logistic regression did show small but nonsignificant differences between the day and shift workers with respect to the risk for ischemic stroke. In some cases, the models with social variables showed a slightly increased risk estimate, the highest being recorded for job strain. In the models with biological variables, the odds ratio was consistently around 1 , with the exception of that for high blood pressure for women, for whom the odds ratio was 0.6 , but not significant.

We tested the logistic models both with age as a continuous variable and with age groups as an indicator variable (results not presented in this analysis), without the results being significantly affected.

\section{Discussion}

The findings of this analysis of a prospective nested case-control study showed no elevated risk for shift workers developing ischemic stroke when they were compared with day workers. The findings are in accordance with those of Karlsson et al (4), and they contradict those of Virtanen \& Notkola (5). Both Karlsson et al (4) and Virtanen \& Notkola (5) performed their analysis in cohort studies. However, only Virtanen \& Notkola included women in their cohort, but their analysis included only blue-collar workers. Nevertheless, Virtanen \& Notkola found a significant excess risk of cerebrovascular death for men working two shifts or evening shifts (relative risk of 1.19) but not for threeshift or night workers. Interestingly, they only found an increased risk for cerebrovascular deaths and not for all cardiovascular deaths with respect to shift workers (5). Tüchsen (16) analyzed stroke morbidity for Danish drivers. He did not make any specific analyses regarding the effects of shift work but claimed that there may be a possible connection between stroke and shift work. Since the diagnosis of stroke events for this study was based solely on clinical presentation, and it was done in accordance with the MONICA protocol, the risk of misclassifying stroke events was probably low.

People that moved out of the northern Sweden MONICA region during the study period were not included in the material and therefore represented a potential loss of cases. We did not find any reason to expect that those who moved out of the region during the period would have had characteristics that differed from those who remained. Therefore, we did not think that this exclusion affected the results in any significant way. Altogether 124 of the participants with diagnosed hypertension received medication for their diagnosis. It was not possible to determine whether this use of medication had any effect on the risk estimate when hypertension was controlled for.

The definition of shift workers in this study was based on data from a single point in time, an average of 5 years before the event. When a definition is based on such data, there is a potential risk of misclassifying workhour exposure. Those who responded that they had day work may in fact be former shift workers and vice versa. Too, there could have been a risk of respondents having trouble in correctly determining their work conditions. Both the risk of misclassification regarding the answers and the fact that the questions used did not take into account the time period during which the present work conditions existed may have led to an underestimation of the risk of shift work itself. Therefore, a shift worker at the time of the questionnaire could in fact have been a day worker up until that day or vice versa (17). This transition increases with age in the direction from shift work to day work.

One finding of this analysis worth mentioning was the relatively small difference between shift workers and day workers regarding the difference in analyzed 
risk factors. Normally, shift workers have a higher prevalence of such risk factors even though it is not a consistent finding in the literature (2).

Another circumstance that could have influenced the results was the fact that this analysis mainly consisted of people under the age of 65 years, since about $80 \%$ of all cases of ischemic stroke usually occur after 65 years of age. Since the official retirement age in Sweden is 65 years, it would be possible to assume that the incidence would have been higher if the age span had been greater. But, in an analysis considering that possibility, the shift work variable would lose some of its validity since most of the participants would be retired and therefore no longer exposed to shift work.

In summary, the findings of this study did not indicate a higher risk of shift workers developing ischemic stroke when they were compared with day workers. The risk estimate was consistent despite the introduction of several recognized risk factors for ischemic stroke.

\section{References}

1. Knutsson A. Health disorders of shift workers. Occup Med (Lond). 2003;53:103-8.

2. Bøggild H, Knutsson A. Shift work, risk factors and cardiovascular disease [review]. Scand J Work Environ Health. 1999;25(2):85-99.

3. Sacco RL, Benjamin EJ, Broderick PJ, Dyken M, Easton JD, Feinberg WM, et al. American Heart Association Prevention Conference, IV: prevention and rehabilitation of stroke: risk factors. Stroke. 1997;28:1507-17.

4. Karlsson B, Alfredsson L, Knutsson A, Andersson E, Torén K. Total mortality and cause-specific mortality of Swedish shiftand day workers in the pulp and paper industry in 1952-2001. Scand J Work Environ Health. 2005;31(1):30-5

5. Virtanen SV, Notkola V. Socioeconomic inequalities in cardiovascular mortality and the role of work: a register study of
Finnish men. Int J Epidemiol. 2002;31:614-21.

6. Stegmayr B, Asplund K. Stroke in Northern Sweden. Scand J Public Health Suppl. 2003;61:60-9.

7. Weinehall L, Westman G, Hellsten G, Boman K, Hallmans G, Pearson T, et al. Shifting the distribution of risk: results of a community intervention in a Swedish programme for the prevention of cardiovascular disease. J Epidemiol Community Health. 1999;53:243-50.

8. Weinehall L, Hallgren C, Westman G, Janlert U, Wall S. Reduction of selection bias in primary prevention of cardiovascular disease through involvement of primary health care. Scand J Prim Health Care. 1998;16:171-6.

9. Tunstall Pedoe H. World Health Organization MONICA Project (Monitoring Trends and Determinants in Cardiovascular Disease): a major international collaboration. J Clin Epidemiol. 1988;41:105-14.

10. Asplund K, Tuomilehto J, Stegmayr B, Wester P, Tunstall Pedoe H. Diagnostic criteria and quality control of the registration of stroke events in the MONICA project. Acta Med Scand Suppl. 1988;728:26-39.

11. Stegmayr B, Asplund K, Wester, PO. Trends in incidence, case-fatality rate, and severity of stroke in northern Sweden, 1985-1991. Stroke. 1994;25:1738-45.

12. Karasek R. Job decision latitude, and mental strain: implications for job redesign. Adm. Sci Q. 1979;24:285-307.

13. Theorell T, Perski A, Åkerstedt T, Sigala F, Ahlberg-Hultén G, Svensson J, et al. Changes in job strain in relation to changes in physiological state: a longitudinal study. Scand J Work Environ Health. 1988;14:189-96.

14. Weinehall L, Johnson O, Jansson J, Boman K, Huhtasaari F, Hallmans G, et al. Perceived health modifies the effect of biomedical risk factors in the prediction of acute myocardial infarction: an incident case-control study from northern Sweden. J Intern Med. 1998;243:99-107.

15. von Schenk H, Treichl L, Tilling B, Olsson A. Laboratory and field evaluation of three desk top instruments for blood cholesterol and triglyceride assay. Clin Chem. 1987;33:1230-2.

16. Tüchsen F. Stroke morbidity in professional drivers in Denmark 1981-1990. Int J Epidemiol. 1997;26:989-94.

17. Karlsson B. Metabolic disturbances in shift workers [dissertation]. Umeå (Sweden): Umeå University, 2004.

Received for publication: 18 December 2006 